\title{
How to accurately assess surfactant biodegradation -impact of sorption on the validity of results
}

\author{
Dorota Cierniak ${ }^{1} \cdot$ Marta Woźniak-Karczewska ${ }^{2} \cdot$ Anna Parus $^{2} \cdot$ Bogdan Wyrwas $^{1} \cdot$ Andreas P. Loibner $^{3}$.

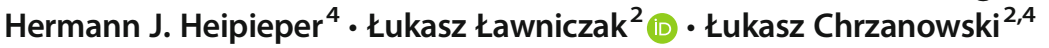

Received: 9 September 2019 / Revised: 9 October 2019 / Accepted: 19 October 2019 / Published online: 15 November 2019

(C) The Author(s) 2019

\begin{abstract}
Surfactants not only are widely used in biotechnological processes but also constitute significant contaminants of the modern world. Among many reports, there is a shortage of works which summarize the issue of surfactant sorption to biomass in a way that would elucidate the biological factors for analysts and analytical factors for microbiologists. The main factor, which is not as obvious as one would expect, is associated with the susceptibility of analytical approaches to errors resulting from incorrect handling of biomass. In case of several publications reviewed in the framework of this study, it was not possible to establish whether the decrease of the analytical signal observed by the authors actually resulted from biodegradation of the surfactant. This review emphasizes the necessity to consider the possibility of surfactant sorption to microbial cells, which may result in significant detection errors as well as conceptual inconsistency. In addition, a reference study regarding representative surfactants (cationic, anionic and non-ionic) as well as yeast, Gram-negative, Gram-positive bacteria, and activated sludge was provided to highlight the possible errors which may arise from disregarding sorption processes when determining degradation of surfactants. This particularly applies to systems which include ionic surfactants and activated sludge as sorption may account for $90 \%$ of the observed depletion of the surfactant. Therefore, a systematic approach was proposed in order to improve the credibility of the obtained results. Finally, the need to employ additional procedures was highlighted which may be required in order to verify that the decrease of surfactant concentration results from biodegradation processes.
\end{abstract}

Keywords Activated sludge $\cdot$ Bacillus cereus $\cdot$ Biodegradation $\cdot$ Pseudomonas putida $\cdot$ Saccharomyces cerevisiae $\cdot$ Sorption . Surfactant

Electronic supplementary material The online version of this article (https://doi.org/10.1007/s00253-019-10202-9) contains supplementary material, which is available to authorized users.

Łukasz Ławniczak

lukasz.lawniczak@put.poznan.pl

1 Institute of Chemistry and Technical Electrochemistry, Poznan University of Technology, Bedrychowo 4, 60-965 Poznan, Poland

2 Institute of Chemical Technology and Engineering, Poznan University of Technology, Pl. M. Skłodowskiej-Curie 2, 60-965 Poznan, Poland

3 IFA-Tulln, BOKU-University of Natural Resources and Life Sciences, 3430 Vienna, Tulln, Austria

4 Department of Environmental Biotechnology, Helmholtz Centre for Environmental Research - UFZ, Permoserstraße 15, 04318 Leipzig, Germany

\section{Introduction}

Surfactants, or surface active agents, comprise a structurally diverse group of chemical compounds which is extensively used in everyday applications. They are present in common cleaning agents, fabric softeners, domestic detergents, and hygienic products such as shampoos, shower gels, and toothpastes (Blagojević et al. 2016; Kurrey et al. 2019). Furthermore, they are commonly utilized as emulsifiers, dispersants, wetting, and foaming agents in several branches of the industry (e.g., in the cosmetic, pharmaceutical, agricultural, food, textile, polymer, and paint sectors) (Traverso-Soto et al. 2016; Palmer and Hatley 2018). Currently, non-ionic surfactants are the dominant group with approx. $40 \%$ of the total market share, which experienced a steady increase of demand during the last years (Allied Market Research 2017). Anionic surfactants are the next commonly used on the market because of their numerous applications and cost-efficient production. Cationic surfactants are 
more expensive and, therefore, constitute a smaller share of the market. In the last decades, surfactants of biological origin, biosurfactants, have gained increasing interest, due to their environmental friendliness (Chrzanowski et al. 2012a; Ławniczak et al. 2013). However, their physicochemical behavior is similar to their synthetic counterparts (Chrzanowski et al. 2012b; Owsianiak et al. 2009a, b).

As a consequence, surfactants are the major constituents of both municipal (Aloui et al. 2009) and industrial wastewater (Ławniczak and Marecik 2019). In addition, they are intentionally introduced into the environment in high amounts for the remediation of oil spills (Peziak et al. 2013; Szulc et al. 2014; Trellu et al. 2016; Lamichhane et al. 2017; Ren et al. 2018) - for example, approximately 7 million liters of Corexit ${ }^{\circledR}$ were applied after the Deepwater Horizon oil spill in 2010 (Rahsepar et al. 2016; McFarlin et al. 2018).

Due to their common discharge into the environment, surfactants are among the most important environmental pollutants (Wyrwas et al. 2013; Menzies et al. 2017). They often exhibit potent biological activity, i.e., interaction with cellular membranes and disruption of important biochemical processes, and may therefore negatively affect living organisms (especially in case of marine environments) (Wyrwas et al. 2011; Rebello et al. 2014; Pereira et al. 2015). As a result, it is imperative to monitor the concentration of surfactants and to keep the amount of surfactants remaining in the environment at minimum by developing efficient methods of their (biological) elimination (Garcia et al. 2016; Sakai et al. 2017; Atashgahi et al. 2018) and replacing more persistent surfactants by biodegradable alternatives (Chrzanowski et al. 2009, 2011). The importance of these tasks is highlighted by several comprehensive reviews regarding the fate of surfactants in the environment (Mungray and Kumar 2009; Könnecker et al. 2011; Cowan-Ellsberry et al. 2014; Jackson et al. 2016). The relevance of this topic is confirmed by the fact that numerous scientific reports focused on the biodegradation of surfactants were published to date (Kara Murdoch et al. 2018; Fedeila et al. 2018; Barra Caracciolo et al. 2019; Nguyen and Oh 2019).

However, it should be noted that the protocols used for assessment of surfactant biodegradability differ notably in terms of the quality of obtained results (Fig. 1). Numerous approaches regarding the determination of surfactants are based solely on the decrease of the analytical signal attributed to the concentration of the studied compound (Zembrzuska et al. 2016). While such methods allow for a relatively rapid and simple measurement, the factual value of the produced data may be limited. In these approaches, several crucial considerations, such as the possible biotransformation of the initial surfactant structure into a stable and potentially more toxic metabolite, are not always taken into account. Incomplete biodegradation often results in the formation of more toxic metabolites, which are by far more hazardous than the parent compound, or derivatives with relatively stable structure, which may accumulate in the environment. Both cases result in major environmental risks despite the fact that the biodegradation assay may suggest complete removal of the initial structure. The lack of biomass growth monitoring methods leads to false assumptions, especially in case of systems with multiple carbons sources. Furthermore, surfactants often exhibit a notable tendency for sorption (He et al. 2015). Although this issue is usually addressed in case of environmental matrices, particularly in case of sediment or soil samples (Corada-Fernández et al. 2018), the fact that sorption of surfactants to biomass may also occur is often overlooked. This corresponds well with the case of mycotoxins, which often exhibit a tendency to bind to the cell pellet, especially in case of lactic acid bacteria. Haskard et al. (2001) observed the extracellular binding of aflatoxin-B1 to the surface of Lactobacillus rhamnosus and established that this process is based on weak non-covalent interactions. Furthermore, El-
Fig. 1 Conceptual summary of considerations and possible consequences which should be considered in surfactant biodegradation studies

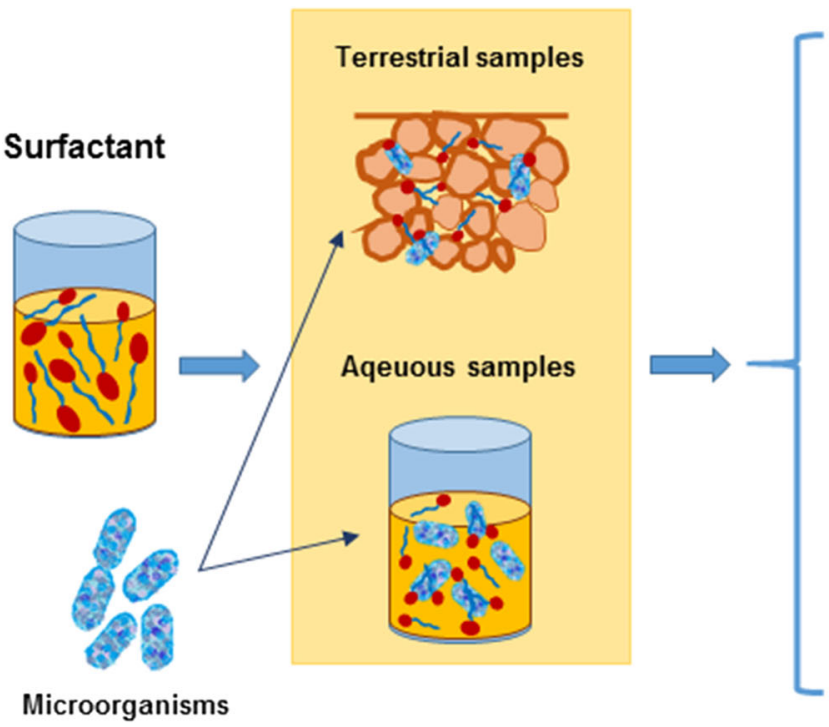

BIODEGRADATION ASSESSMENT

Primary biodegradation Ultimate biodegradation

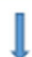

CONSIDERATIONS

Accumulation of metabolites Monitoring of biomass growth Sorption of surfactants to various sorbents

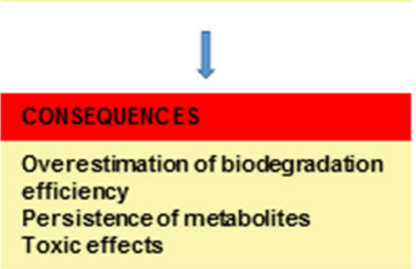


Nezami et al. (2002) reported that approx. 55\% of zearalenone was instantly bound to the cells of Lactobacillus strains and indicated that the binding efficiency is directly influenced by the bacterial concentration. The studies imply that binding of toxins on the surface of cells may often be their major removal mechanism. While this phenomenon is positive in terms of reducing the impact of mycotoxins on human health, it is a major disadvantage in terms of analytical procedures. It should also be emphasized that binding may also occur in case of dead biomass, which makes the quantification of biodegradation processes even more challenging. This may contribute to significant consequences, which include notable errors in terms of actual quantification of surfactants, misinterpretation of data regarding their actual environmental impact, and, in consequence, to inconsistency in the current state of the art.

In the framework of this study, recent reports focusing on surfactant biodegradation were reviewed in terms of variety of the employed analytical approaches and the consistency of obtained data with the established conclusions. Furthermore, the importance of surfactant sorption to biomass is highlighted on the basis of original research results. The aim of this review is to (i) identify the limitations of different methods used for the determination of surfactant biodegradation, to (ii) discuss the issues which may be a common source of scientific bias, and to (iii) elucidate adequate guidelines for future experiments used for the assessment of the environmental fate of surfactants.

\section{Consideration 1: possible biodegradation scenarios}

In order to properly evaluate the biodegradability of surfactants, it is necessary to understand the nature of biodegradation processes. As a general concept, "biodegradation" is the transformation of a given compound into a product characterized by a less complex chemical structure carried out by biological factors, mainly microorganisms (Neilson and Allard 2008). This definition can be further narrowed in order to distinguish two following terms: primary biodegradation, which corresponds to the dissipation of the parent compound, and ultimate biodegradation, which is associated with the complete mineralization of a given compound resulting in the formation of $\mathrm{CO}_{2}, \mathrm{H}_{2} \mathrm{O}$, energy, and biomass. A conceptual scheme regarding the test systems which are used to investigate primary and ultimate biodegradation is presented in Fig. 2.

Test systems focused of the determination of primary biodegradation efficiency rely on the detection of the analytical signal attributed to the primary compound (in this case, the initial structure of the surfactant). The efficiency of primary biodegradation is calculated based on the decrease of this analytical signal. Detection is frequently carried out using a spectrophotometric approach; however, in cases when the surfactant occurs in the form of a mixture of homologues (e.g., Triton X-100) or when the analyte is present in a complex environmental matrix (e.g., soil), chromatographic methods are typically employed (usually HPLC, GC is also used although less frequently). The analytical procedures often require additional steps, e.g., derivatization.

Systems dedicated to the analysis of ultimate biodegradation investigate the efficiency of conversion of the primary compound to the most basic final metabolite - carbon dioxide. Assuming that microbial activity is not completely inhibited by the analyzed surfactant, the amount of evolved $\mathrm{CO}_{2}$ constantly increases during the study period and the efficiency of the process is calculated based on its final amount. The analytical procedure requires gas-tight conditions, and the determination is
Fig. 2 General overview of the tests systems employed for assessment of primary and ultimate biodegradation.

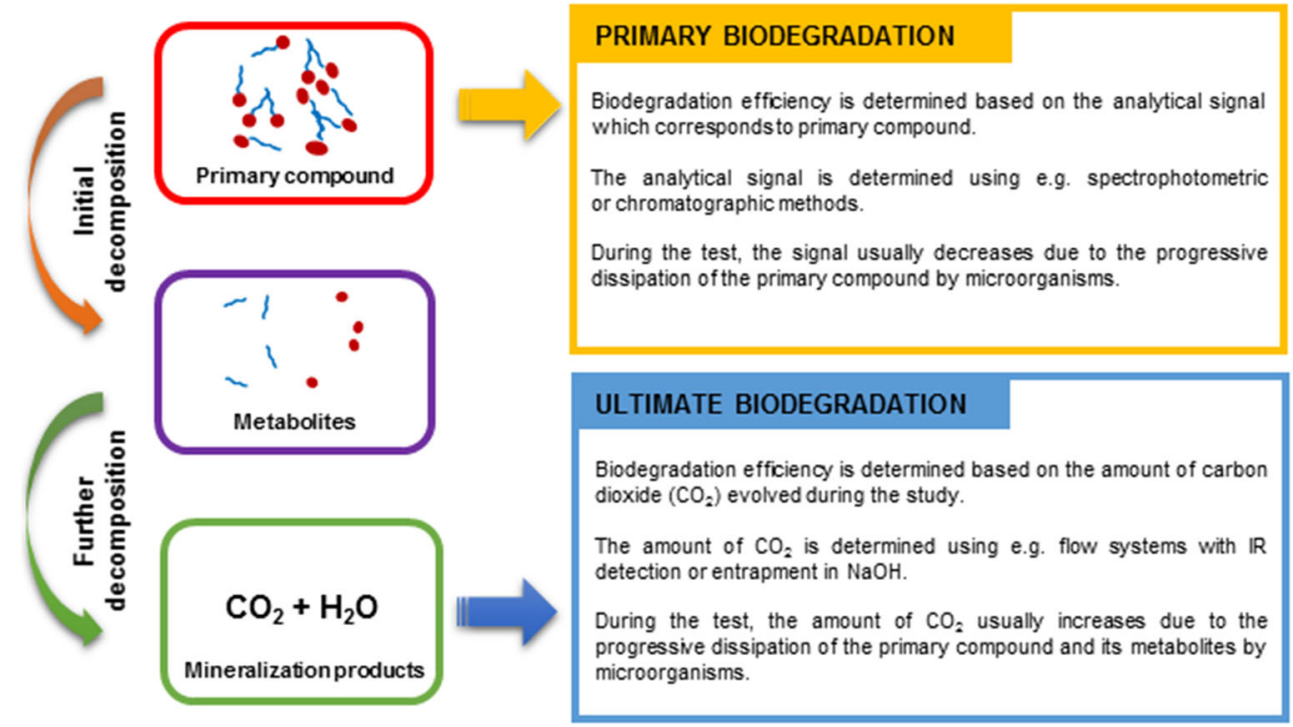


carried out by allowing direct transfer of the analyte to the detector (flow systems) or its entrapment in $\mathrm{NaOH}$ and the use of, e.g., calibrated pressure-sensitive sensors.

It should be emphasized that while both terms refer to processes of biological decomposition, their respective informational value is fundamentally different in terms of the possible fate of surfactants in the environment.

Primary biodegradation or biotransformation is, at best, an estimation of the susceptibility of a selected chemical compound to undergo a structural transformation due to the enzymatic activity of microorganisms (Sydow et al. 2015). Without supplementary assays (e.g., determination of possible metabolites), it does not provide any relevant data regarding the actual environmental impact of such a transformation (e.g., the stability and toxicity of the formed product). These limitations are often ignored during the interpretation of data, which leads to overestimation of biodegradation and false conclusions.

In this regard, the assessment of ultimate biodegradation or biomineralization is a more credible source of data for analysis of environmental impact, as it assumes a complete removal of both the initial compound and all subsequent metabolites (OECD, 301 1992). Furthermore, the measurement of carbon dioxide evolution directly reflects the activity of microorganisms and may hence indicate the occurrence of any toxic effects. While experimental setups based on ultimate biodegradation require adequate preparation to warrant acceptable accuracy of data, they contribute to a more comprehensive elucidation of environmental hazards.

The common mental shortcut, associated with the use of the general term "biodegradation" as an abbreviation which actually refers to experiments focused on primary biodegradation, is the main source of conceptual bias in numerous scientific reports.

\section{Consideration 2: depletion of surfactants not associated with biodegradation}

Due to the common prevalence of surfactants in the environment, ease of use and low analysis time have become important traits of methods used for their monitoring (Shaharom et al. 2018). As a result, procedures which allow for accurate and rapid measurement of surfactant concentrations have attracted much popularity. Nevertheless, it should be noted that excessive simplification of analysis protocols may also contribute to a flawed interpretation. Numerous methods used for detection and quantification of surfactants (e.g., with the use of chromatography or spectrophotometry) rely on the differentiation between the analytical signals measured for initial and final samples in order to evaluate the depletion of surfactants. Therefore, the second major conceptual pitfall is associated with the fact that the determined decrease of surfactant content in a system comprising microorganisms is often unconditionally attributed to its biodegradation.

In order to properly identify the cause for the observed surfactant depletion, the entire analytical protocol has to be taken into consideration (Fig. 1). It has to be emphasized that, due to their amphiphilic structure, surfactants exhibit a strong tendency to adsorb to virtually any given surface (Langevin 2014). While in most cases desorption processes allow for satisfactory recovery of surfactants into the bulk phase, the potential of an irreversible loss of a fraction of surfactants should always be considered. This possibility is of particular importance in the case of relatively simple experimental designs (e.g., flasks studies), which only measure the reduction of the native compound but do not account for individual mechanisms that are able to reduce the effective concentration of surfactants in the test setup. A momentary depletion may be caused by the sorption of surfactants to the walls of the vessel used for experiments, regardless of the material (glass, steel, ceramics) (Timmer and Droge 2017). Surfactants may also be strongly bound to the interface of a liquid-liquid system (Langevin 2014), which also leads to the decrease of their content during extraction steps. The obvious loss of the analyte resulting from any employed filtration steps should also be accounted for in the final calculations. However, interactions between surfactants and microbial cells are perhaps the most often disregarded reason for analytical bias in biodegradation studies.

\section{Consideration 3: sorption to biomass}

The fact that surfactants do affect cellular membranes is well known and commonly accepted. Several comprehensive reports confirmed that surfactant-mediated destabilization and subsequent disruption of cell membranes due to the formation of mixed surfactant-phospholipid micelles is one of the major mechanisms associated with the toxicity of surfactants (Carmona-Ribeiro and de Melo Carrasco 2013; Borkowski et al. 2016; Liu et al. 2016). Taking into account that incorporation of surfactants into the phospholipid bilayer cannot be considered a scientific novelty to date, it is surprising that this phenomenon is often neglected in case of biodegradation trials.

The majority of analytical procedures require the separation of cells from the medium (e.g., by centrifugation), and subsequent determination procedures are usually focused solely on the supernatant. Questions addressing how much of the original surfactant content is lost due to sorption on the biomass pellet and whether this amount is of any relevance or if it may be safely neglected often remain unanswered. In order to underline the importance of this issue, results of an original study focusing on the sorption of surfactants onto biomass are presented below (Fig. 3). 
The objective of this investigation was to determine surfactant sorption (constant concentration of $10 \mathrm{mg} / \mathrm{L}$ ) to different types of biomass considering the following main groups of microorganisms: Bacillus cereus (Gram-positive bacteria), Pseudomonas putida (Gram-negative bacteria), Saccharomyces cerevisiae (yeast), and activated sludge (most commonly tested complex mixed culture). The relevant values of biomass $(\mathrm{g} / \mathrm{L})$ corresponding to OD values presented for each studied microbial system in Fig. 3 are given in Table S1 in the Online Resource. Furthermore, calibration curves for the analytical procedures were presented in Figures S1-S3, whereas the reagents used for the experiments and calculations of LOD, LOQ, and RSD were presented in Tables S2S9 in the Online Resource. The decrease of the analytical signal associated with the surfactant content was measured 1 min after contact of the biomass and the surfactant (Fig. 2). Analysis of the obtained results revealed three important implications. Firstly, sorption of surfactants depends on their type, i.e., the chemical structure. The following order which describes the susceptibility of surfactants to sorption on biomass may be established: cationic surfactants $>$ anionic surfactants $>>$ non-ionic surfactants. Sorption of cationic surfactants reached the highest values at the lowest corresponding OD (or $\mathrm{g} / \mathrm{L}$ in case of activated sludge), regardless of the tested systems. Anionic surfactants exhibited a moderate tendency for sorption on biomass, whereas sorption of non-ionic surfactants was marginal for the majority of the studied biomass types (Fig. 3).

Secondly, the extent of surfactant sorption differed with regard to the type of microorganisms used in the study. For example, at the lowest biomass concentration $(\mathrm{OD}=0.1$ or $0.05 \mathrm{~g} / \mathrm{L}$ in case of activated sludge), the content of cationic surfactants was reduced by $80-90 \%$ in systems comprising $P$. putida and activated sludge biomass, whereas in case of $B$. cereus and yeast cells, the reduction amounted to 30 $40 \%$. It should also be emphasized that notable sorption of non-ionic surfactants was observed only in case of activated sludge biomass (15-90\% depending on the OD value).

Finally, the sorption of surfactants increased with the increase of the amount of biomass in the system. This effect was most apparent for anionic surfactants, as a gradual intensification of sorption was established for all studied systems
Fig. 3 Sorption of surfactants (square - cationic, diamondanionic, circle - non-ionic; initial concentration of $10 \mathrm{mg} / \mathrm{L}$ ) after short-term exposure (1 $\mathrm{min})$ to monoculture biomass (a P. putida, b $B$. cereus, c $S$. cerevisiae) at different concentrations (expressed as OD, ranging from 0.1 to 12 )
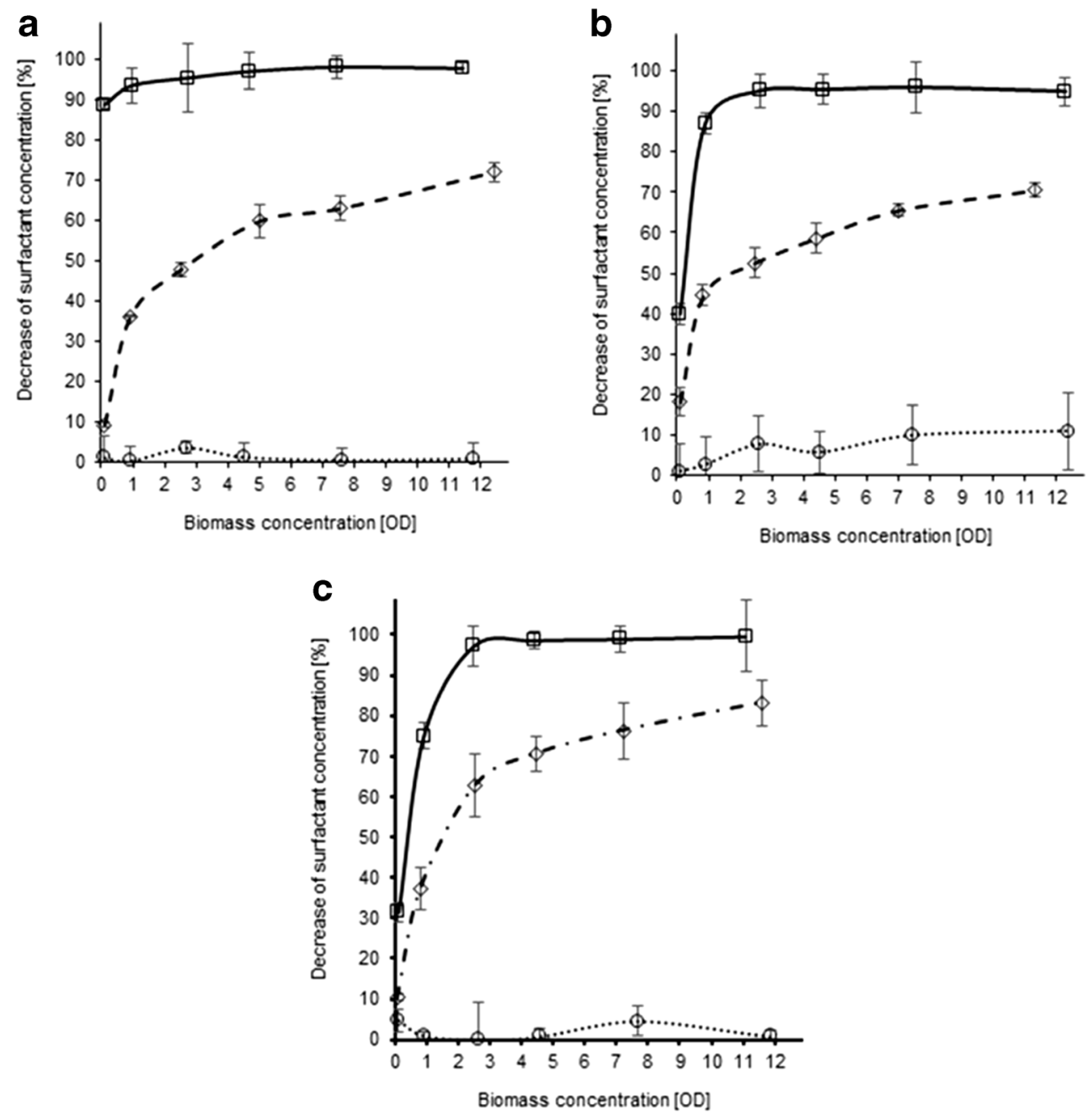
(usually from approx. $10 \%$ to values $>70 \%$ ). Even after the first increase of biomass concentration, the sorption was increased by a factor of two to five, depending on the type of biomass used for the experiment.

The notably higher affinity of cationic surfactants towards biomass may be explained by the structure of the cell envelope. The surfaces of microbial cells are characterized by an overall negative charge, due to the presence of teichoic acids in cell walls of Gram-positive bacteria, lipopolysaccharides in cell walls of Gram-negative bacteria (Van Loosdrecht et al. 1987; Magnusson and Johansson 1977), and phosphate groups in cell walls of yeast (Wilcocks and Smart 1995), which facilitate the transport of cationic surfactants from the bulk phase into the direct vicinity of the cells via electrostatic attraction (García et al. 2006). At this point, interactions of specific surfactant types with the phospholipid bilayer, which correspond to the initial stages of membrane solubilization mechanism, become the predominant factor (Otzen 2017). The surfactant monomer penetrates through the extracellular compounds and inserts into the bilayer (Jones 1999). Since both cationic and anionic surfactants are usually characterized by a strictly defined amphiphilic structure (the charged hydrophilic "head" may be easily distinguished from the hydrophobic "tail"), which closely resembles that of a phospholipid unit, they may be preferentially incorporated into the lipid section of the bilayer (Markiewicz et al. 2015), which corresponds well with their high sorption. In contrast, the structure of non-ionic surfactants deviates from the classic head-tail approach, which may render their embedding into the membrane hindered. Additionally, there are reports regarding membrane domains based on sphingolipids and cholesterol, which limit the membrane solubility processes by Triton X100 (Koynova and Tenchov 2001). This may also explain the low sorption of the non-ionic surfactants to the biomass of studied monocultures. The fact that highest sorption was observed in case of experiments involving activated sludge biomass may be attributed to the formation of flocs (BaenaNogueras et al. 2013). This peculiar matrix, which consists of cells incorporated in extracellular polymeric substances (EPS), is characterized by a notably higher surface area compared to traditional biofilms or planktonic cells. Furthermore, the presence of EPS may contribute to additional interactions, which would explain the higher sorption of non-ionic surfactants. Consequently, increased amount of biomass corresponds to enhanced sorption of the surfactants.

\section{Recommendations for accurate biodegradation assessment}

The previously described phenomena may directly result in the overestimation of surfactant biodegradation efficiency.
The overview of analytical protocols used for the determination of surfactant biodegradability in recently published scientific reports (presented in Table 1) revealed that in numerous cases, it is impossible to clearly distinguish whether the reduction of surfactant concentration occurred due to biodegradation or sorption. This particularly applies to studies in which the quantification of the surfactant content was based solely on the decrease of the analytical signal of the native compound. It should also be emphasized that the majority of the reviewed studies was carried out with the use of activated sludge, which exhibited the highest sorption capacity of surfactants in our study. Based on the investigated reports, the following guidance was formulated which will allow to obtain accurate and reliable biodegradation results (Fig. 4).

Figure 5 presents recommended approaches for evaluating the biodegradation of surfactants divided into four tiers with a gradually increasing informational value regarding the environmental impact and reduced chances of bias. The bottom of tier 1 (primary biodegradation) is practically limited to the estimation of residual concentrations of the primary compound. When studies regarding sorption are included, the informational value of the approach is increased to the level of the bottom of tier 2 (ultimate biodegradation). At this level, it is possible to evaluate the amount of primary compound which was biodegraded and the residues with relatively high accuracy. To further elucidate the fate of the biodegraded surfactant, it is necessary to include an analysis of the metabolites formed during the process and to identify any stable and persistent structures. This step allows to reach the bottom of tier 3 (total mass balance). At this point, the studies should allow to establish the residual concentration of the surfactant, the decrease of surfactant content due to sorption (both abiotic and biotic), formation of stable metabolites due to transformation of initial surfactant structure, and dissipation of the surfactant. The "missing piece of the puzzle" is associated with the amount of surfactant which was used by the microorganisms as a source of carbon for anabolic processes. In consequence, it is advised to additionally monitor the biomass in order to ensure that decrease of the surfactant content correlates with cellular growth. This results in a highly accurate and credible evaluation, which is roughly at a similar level to tier 4-total mass balance using isotope-labelled compounds.

To summarize, in cases when studies are focused exclusively on primary biodegradation of surfactants, the implementation of surfactant sorption into the analytical protocol is a basic requirement which is necessary to exclude potential inconsistency of results. Moreover, in order to properly address the actual environmental impact of the tested compounds, such studies should include additional analyses, such as determination of potential metabolites (which especially applies to commonly used and commercially available surfactants) and evaluation of microbial growth (which indicates that the decrease of surfactant content may be attributed to 


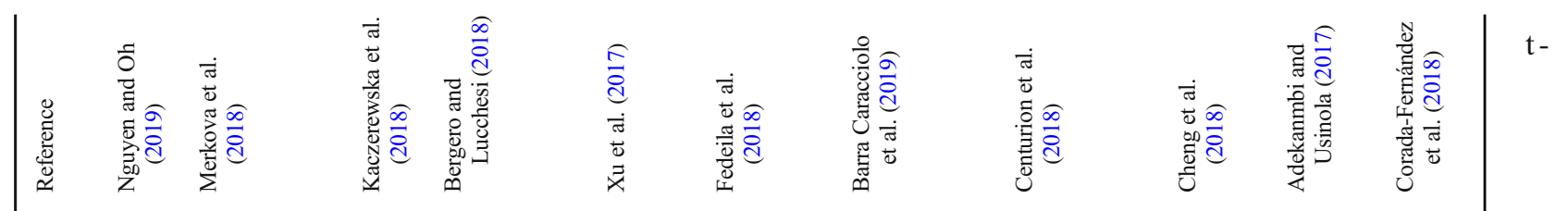

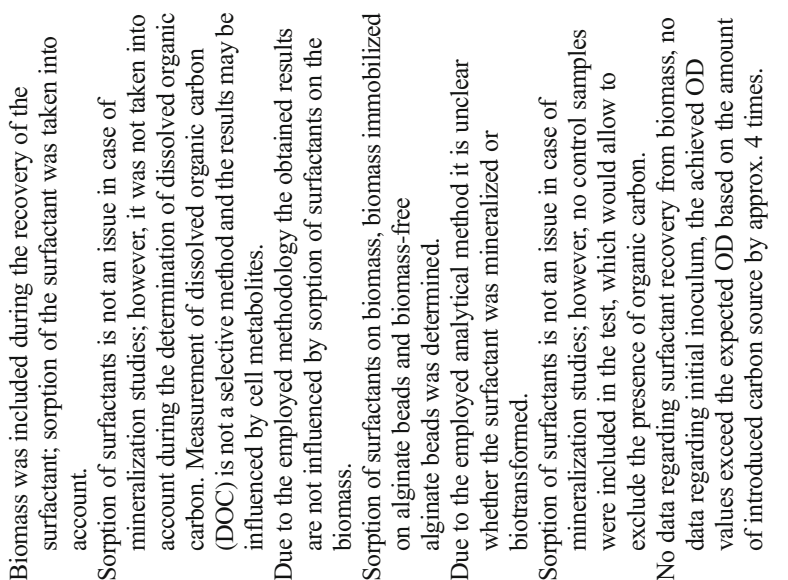

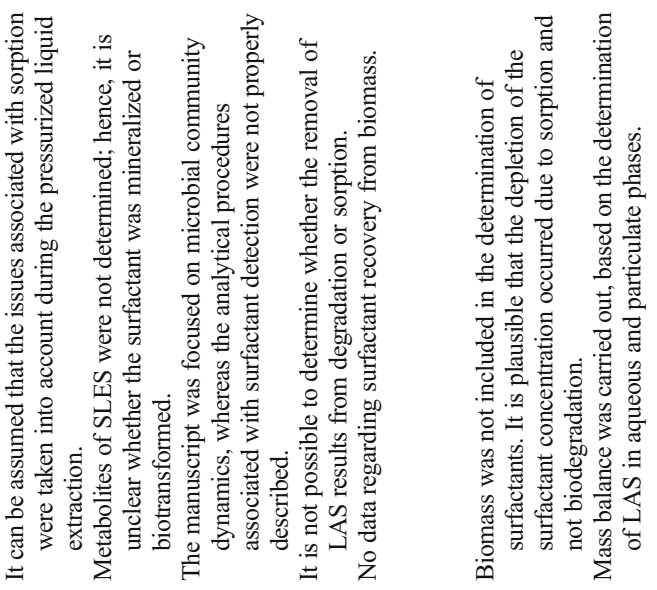

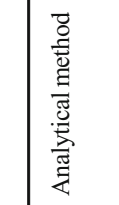

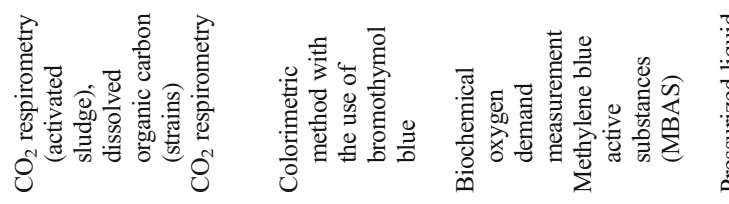

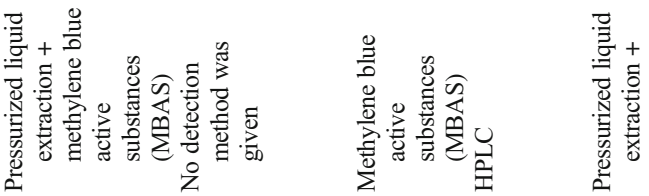

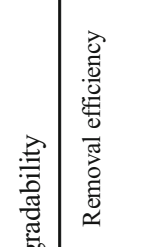

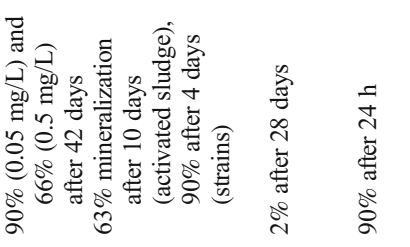

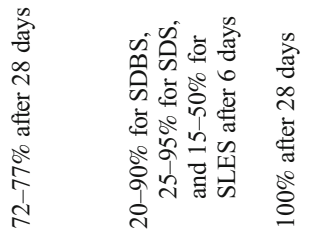

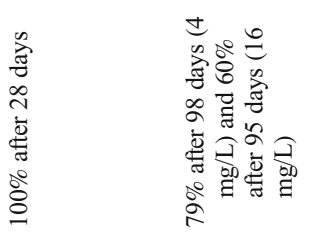

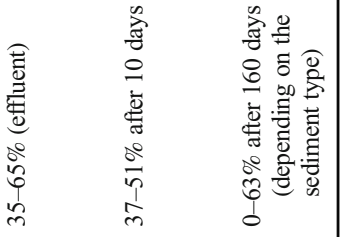

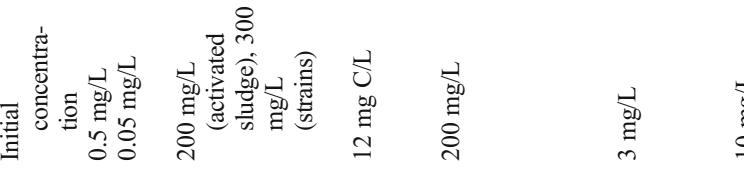

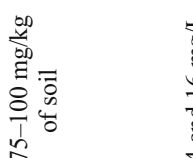

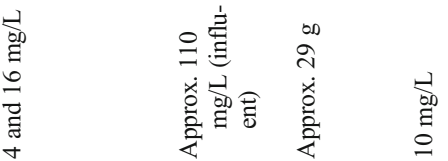

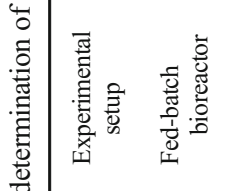

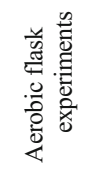

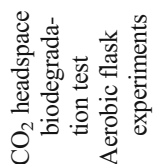

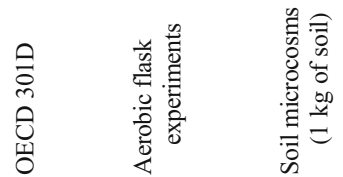

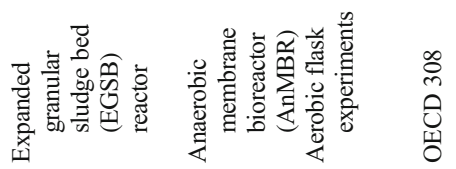

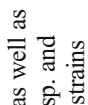

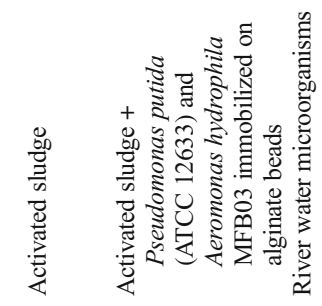

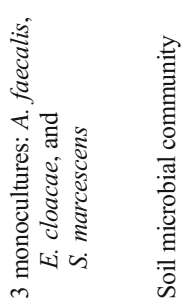

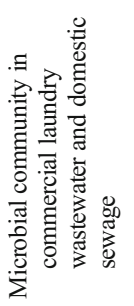

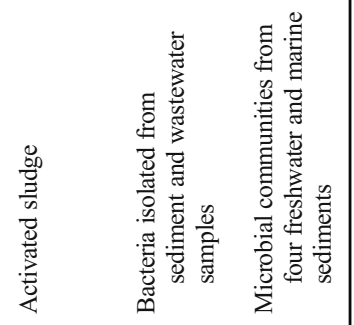

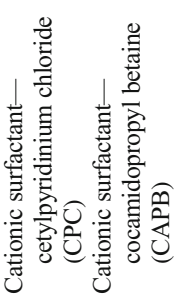

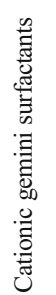

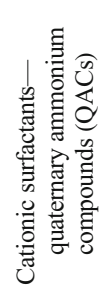

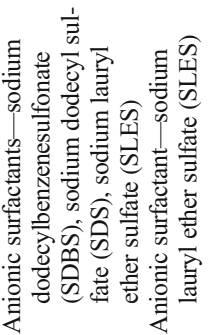

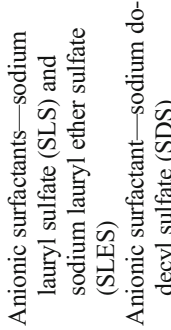

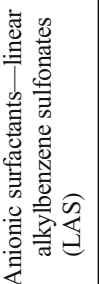




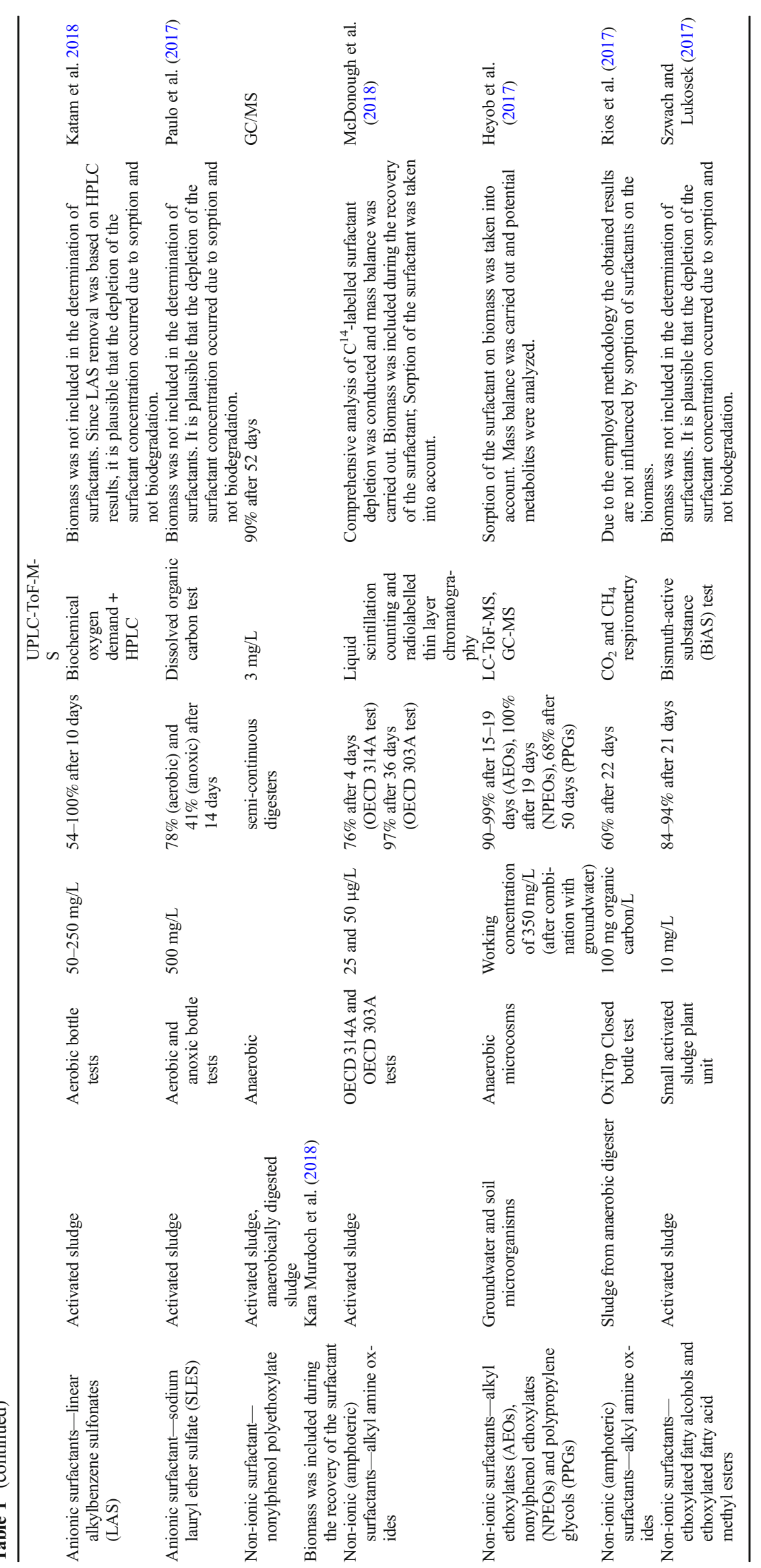




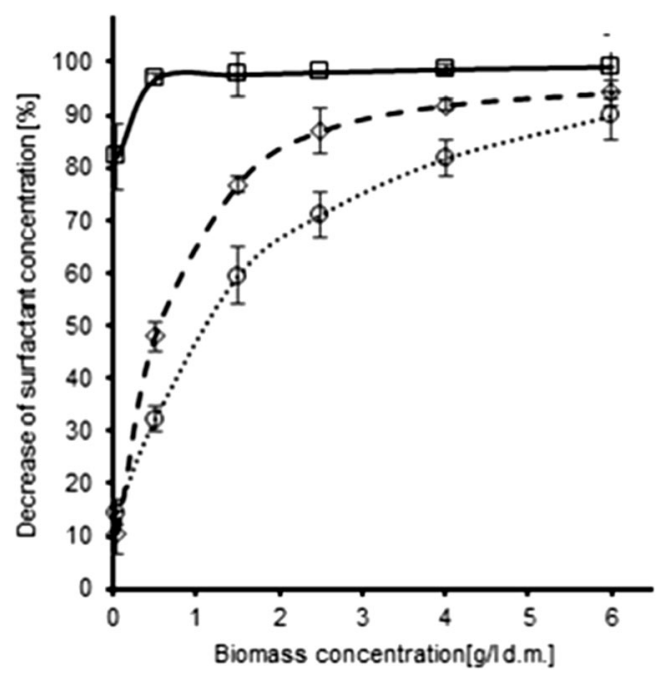

Fig. 4 Sorption of surfactants (square- $-\square-$ cationic, diamond $-\triangleright$ anionic, circle - $\mathrm{O}-$ non-ionic; initial concentration of $10 \mathrm{mg} / \mathrm{Ll}$ ) after short- term exposure $(<1 \mathrm{~min})$ to activated sludge biomass at different concentrations (expressed as g of dry matter per literlitre, ranging from 0.05 to 6 ).

he activity of microorganisms and allows to monitor potential toxic effects). Methods based on isotope-labelled compounds are characterized by the highest compliance with this approach as they also indicate the amount of studied compound which is incorporated into the biomass; however, their use is not always feasible due to high costs and the necessity to employ dedicated analytical apparatuses. Mass balance based on non-labelled compounds may also be carried out, assuming that the recovery of surfactants, determination of metabolites, and evaluation of carbon dioxide are included in the analytical protocol.

In conclusion, based on the list of reviewed publications as well as numerous earlier reports, it is evident that analytical approaches focused on the determination of surfactant

Fig. 5 Tiered approach for increasing the accuracy of surfactant biodegradation test biodegradation vary in terms of numerous practical aspects (ease of use, duration, selectivity, limits of detection and quantification, etc.). A major difference, which is not as obvious as can be expected, is associated with the susceptibility of such approaches to errors resulting from improper handling of biomass. In case of several publications reviewed in the framework of this study, it was not possible to establish whether the decrease of the analytical signal observed by the authors actually resulted from biodegradation of the surfactant. Without a comprehensive preparation of the experimental system, which includes the indication of possible sources of errors and development of appropriate counter-measures, the accuracy of the obtained results may be questionable.

We emphasize the necessity to consider the possibility of surfactant sorption onto microbial cells, which may result in significant detection errors as well as conceptual inconsistency. This particularly applies to systems which include ionic surfactants and activated sludge as sorption may account for 90\% of the observed depletion of the surfactant. Coincidentally, such systems are most commonly applied in degradation studies, which further highlight the importance of this issue.

We propose a systematic approach in order to improve the credibility of the obtained results and limit the uncertainty which may result from sorption. Depending on the employed experimental setup, additional procedures such as determination of sorption to various elements of the test system, analysis of metabolites formed after the decomposition of the primary compound, and control of biomass growth may be required in order to verify that the decrease of surfactant concentration results from biodegradation processes.

Funding information

Financial support is given by the European Union's Horizon 2020 research and innovation program under grant agreement no. 633962 for the project P4SB.

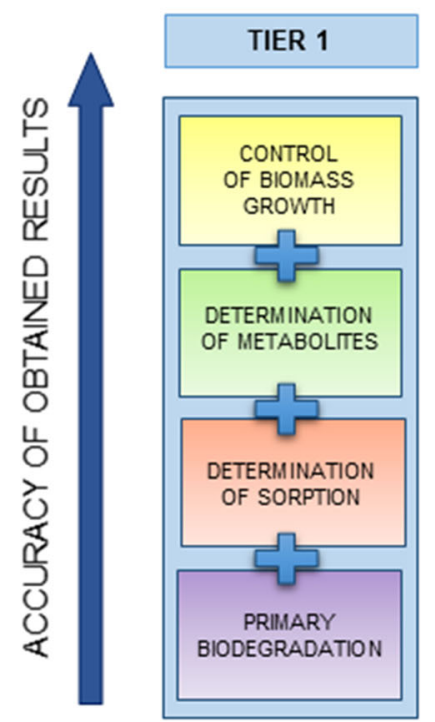

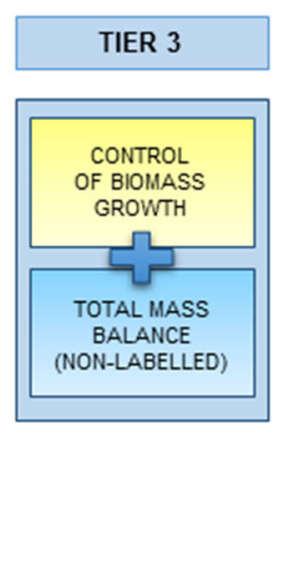
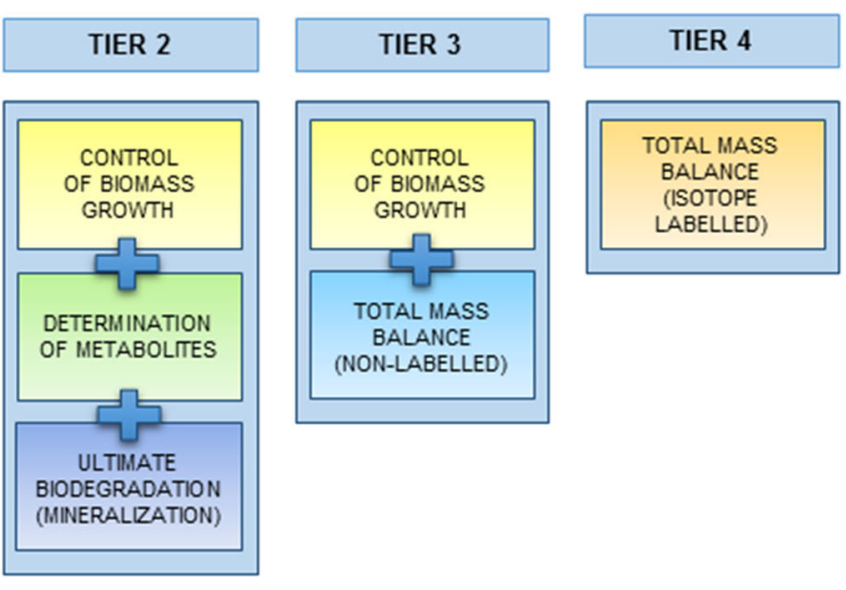


\section{Compliance with ethical standards}

Conflict of interest The authors declare that they have no conflict of interest.

Ethical statement This article does not contain any studies with human participants or animals.

Open Access This article is distributed under the terms of the Creative Commons Attribution 4.0 International License (http:// creativecommons.org/licenses/by/4.0/), which permits unrestricted use, distribution, and reproduction in any medium, provided you give appropriate credit to the original author(s) and the source, provide a link to the Creative Commons license, and indicate if changes were made.

\section{References}

Adekanmbi AO, Usinola IM (2017) Biodegradability and aquatic toxicity of quaternary ammonium-based gemini surfactants - effect of the spacer on their ecological properties. Jordan J Bio Sci 10:251-255

Allied Market Research (2017) Surfactants market by type (cationic, anionic, nonionic, amphoteric, and others) and application (household detergent, personal care, industrial \& institutional cleaner, oilfield chemical, agricultural chemical, food processing, paint \& coating, adhesive, plastic, textile, and others) - Global Opportunity Analysis and Industry Forecast, 2018-2025.

Aloui F, Kchaou S, Sayadi S (2009) Physicochemical treatments of anionic surfactants wastewater: effect on aerobic biodegradability. J Hazard Mater 164:353-359

Atashgahi S, Sánchez-Andrea I, Heipieper HJ, van der Meer JR, Stams AJM, Smidt H (2018) Prospects for harnessing biocide resistance for bioremediation and detoxification. Science 360:743-746

Baena-Nogueras RM, Gonzalez-Mazo E, Lara-Martín PA (2013) Determination and occurrence of secondary alkane sulfonates (SAS) in aquatic environments. Environ Pollut 176:151-157

Barra Caracciolo A, Ademollo N, Cardoni M, Di Giulio A, Grenni P, Pescatore T, Rauseo J, Patrolecco L (2019) Assessment of biodegradation of the anionic surfactant sodium lauryl ether sulphate used in two foaming agents for mechanized tunnelling excavation. J Hazard Mater 365:538-545

Bergero MF, Lucchesi GI (2018) Degradation of cationic surfactants using immobilized bacteria: its effect on adsorption to activated sludge. J Biotechnol 272-273:1-6

Blagojević SN, Blagojević SM, Pejić ND (2016) Performance and efficiency of anionic dishwashing liquids with amphoteric and nonionic surfactants. J Surfactants Deterg 19:363-372

Borkowski A, Ławniczak Ł, Cłapa T, Narozna D, Selwet M, Peziak D, Markiewicz B, Chrzanowski Ł (2016) Different antibacterial activity of novel theophylline-based ionic liquids - growth kinetic and cytotoxicity studies. Ecotoxicol Environ Saf 130:54-64

Carmona-Ribeiro AM, de Melo Carrasco LD (2013) Cationic antimicrobial polymers and their assemblies. Int J Mol Sci 14:9906-9946

Centurion VB, Moura AGL, Delforno TP, Okada DY, Dos Santos VP, Varesche MBA, Oliveira VM (2018) Anaerobic co-digestion of commercial laundry wastewater and domestic sewage in a pilotscale EGSB reactor: the influence of surfactant concentration on microbial diversity. Int Biodeterior Biodegradation 127:77-86

Cheng Z, Wei Y, Zhang Q, Zhang J, Lu T, Pei Y (2018) Enhancement of surfactant biodegradation with an anaerobic membrane bioreactor by introducing microaeration. Chemosphere 208:343-351
Chrzanowski Ł, Meulenkamp R, Kastner M, Wick LY, Heipieper HJ (2009) Rhamnolipid biosurfactants decrease the toxicity of chlorinated phenols to Pseudomonas putida DOT-T1E. Lett Appl Microbiol 48:756-762

Chrzanowski Ł, Owsianiak M, Szulc A, Marecik R, Piotrowska-Cyplik A, Olejnik-Schmidt AK, Staniewski J, Lisiecki P, Ciesielczyk F, Jesionowski T, Heipieper HJ (2011) Interactions between rhamnolipid biosurfactants and toxic chlorinated phenols enhance biodegradation of a model hydrocarbon-rich effluent. Int Biodeterior Biodegradation 65:605-611

Chrzanowski Ł, Ławniczak Ł, Czaczyk K (2012a) Why do microorganisms produce rhamnolipids? World J Microbiol Biotechnol 28:401419

Chrzanowski Ł, Dziadas M, Ławniczak Ł, Cyplik P, Białas W, Szulc A, Lisiecki P, Jeleń H (2012b) Biodegradation of rhamnolipids in liquid cultures: effect of biosurfactant dissipation on diesel fuel/B20 blend biodegradation efficiency and bacterial community composition. Biores Technol 111:328-335

Corada-Fernández C, González-Mazo E, Lara-Martín PA (2018) Evaluation of the anaerobic biodegradation of linear alkylbenzenesulfonates (LAS) using OECD 308 water/sediment systems. J Hazard Mater 360:24-31

Cowan-Ellsberry C, Belanger S, Dorn P, Dyer S, Mcavoy D, Sanderson H, Versteeg D, Ferrer D, Stanton K (2014) Environmental safety of the use of major surfactant classes in North America. Crit Rev Environ Sci Technol 44:1893-1993

El-Nezami H, Polychronaki N, Salminen S, Mykkänen H (2002) Binding rather than metabolism may explain the interaction of two foodgrade Lactobacillus strains with zearalenone and its derivative $\alpha$ zearalenol. Appl Environ Microbiol 68:3545-3549

Fedeila M, Hachaïchi-Sadouk Z, Bautista LF, Simarro R, Nateche F (2018) Biodegradation of anionic surfactants by Alcaligenes faecalis, Enterobacter cloacae and Serratia marcescens strains isolated from industrial wastewater. Ecotoxicol Environ Saf 163:629635

García MT, Campos E, Sánchez-Leal J, Comelles F (2006) Sorption of alkyl benzyl dimethyl ammonium compounds by activated sludge. $\mathrm{J}$ Dispers Sci Technol 27:739-744

Garcia MT, Kaczerewska O, Ribosa I, Brycki B, Materna P, Drgas M (2016) Biodegradability and aquatic toxicity of quaternary ammonium-based gemini surfactants: effect of the spacer on their ecological properties. Chemosphere 154:155-160

Haskard CA, El-Nezami HS, Kankaanpää PE, Salminen S, Ahokas JT (2001) Surface binding of aflatoxin B1 by lactic acid bacteria. Appl Environ Microbiol 67:3086-3091

He Y, Yazhgur P, Salonen A, Langevin D (2015) Adsorption-desorption kinetics of surfactants at liquid surfaces. Advances in Colloid and Interface Science 222:377-384

Heyob KM, Blotevogel J, Brooker M, Evans MV, Lenhart JJ, Wright J, Lamendella R, Borch T, Mouser PJ (2017) Natural attenuation of nonionic surfactants used in hydraulic fracturing fluids: degradation rates, pathways, and mechanisms. Environ Sci Technol 51:1398513994

Jackson M, Eadsforth C, Schowanek D, Delfosse T, Riddle A, Budgen N (2016) Comprehensive review of several surfactants in marine environments: fate and ecotoxicity. Environ Toxicol Chem 35:10771086

Jones MN (1999) Surfactants in membrane solubilisation. Int J Pharm 177:137-159

Kaczerewska O, Brycki B, Ribosa I, Comelles F, Garcia MT (2018) Cationic gemini surfactants containing an $\mathrm{O}$-substituted spacer and hydroxyethyl moiety in the polar heads: self-assembly, biodegradability and aquatic toxicity. J Ind Eng Chem 59:141-148

Kara Murdoch F, Murdoch RW, Gürakan GC, Sanin FD (2018) Change of microbial community composition in anaerobic digesters during 
the degradation of nonylphenol diethoxylate. Int Biodeterior Biodegradation 135:1-8

Katam K, Maetani K, Shimizu T, Nakajima J, Bhattacharyya D (2018) Study of aerobic biodegradation of surfactants and fluorescent whitening agents in detergents of a few selected Asian countries (India, Indonesia, Japan, and Thailand). J Water Environ Technol 16:18-29

Könnecker G, Regelmann J, Belanger S, Gamon K, Sedlak R (2011) Environmental properties and aquatic hazard assessment of anionic surfactants: physico-chemical, environmental fate and ecotoxicity properties. Ecotoxicol Environ Saf 74:1445-1460

Koynova R, Tenchov B (2001) Interactions of surfactants and fatty acids with lipids. Curr Opin Colloid Interface Sci 6:277-286

Kurrey R, Mahilang M, Deb MK, Shrivas K (2019) Analytical approach on surface active agents in the environment and challenges. Trends Environ Analytical Chem 21:e0061

Lamichhane S, Bal Krishna KC, Sarukkalige R (2017) Surfactantenhanced remediation of polycyclic aromatic hydrocarbons: a review. J Environ Manage 199:46-61

Langevin D (2014) Rheology of adsorbed surfactant monolayers at fluid surfaces. In: Davis SH, Moin P (eds.) Annu Rev Fluid Mech 46:4765.

Ławniczak Ł, Marecik R (2019) Comparison of metalworking fluids biodegradation efficiency by autochthonous and environmental communities. J Environ Manage 232:625-635

Ławniczak Ł, Marecik R, Chrzanowski Ł (2013) Contributions of biosurfactants to natural or induced bioremediation. Appl Microbiol Biotechnol 97:2327-2339

Liu S, Guo C, Liang X, Wu F, Dang Z (2016) Nonionic surfactants induced changes in cell characteristics and phenanthrene degradation ability of Sphingomonas sp. GY2B. Ecotoxicol Environ Saf 129:210-218

Magnusson KE, Johansson G (1977) Probing the surface of Salmonella typhimurium and Salmonella minnesota SR and R bacteria by aqueous biphasic partitioning in systems containing hydrophobic and charged polymers. FEMS Microbiol Lett 2:225-228

Markiewicz M, Jungnickel C, Cho C-W, Stolte S (2015) Mobility and biodegradability of an imidazolium based ionic liquid in soil and soil amended with waste sewage sludge. Environ Sci Process Impacts 17:1462-1469

McDonough K, Itrich N, Menzies J, Casteel K, Belanger S, Wehmeyer K (2018) Environmental fate of amine oxide: using measured and predicted values to determine aquatic exposure. Sci Total Environ 616-617:164-171

McFarlin KM, Perkins MJ, Field JA, Leigh MB (2018) Biodegradation of crude oil and Corexit 9500 in Arctic seawater. Front Microbiol 9: 1788

Menzies JZ, McDonough K, McAvoy D, Federle TW (2017) Biodegradation of nonionic and anionic surfactants in domestic wastewater under simulated sewer conditions. Biodegradation 28: $1-14$

Merkova M, Zalesak M, Ringlova E, Julinova M, Ruzicka J (2018) Degradation of the surfactant cocamidopropyl betaine by two bacterial strains isolated from activated sludge. Int Biodeter Biodegr 127:236-240

Mungray AK, Kumar P (2009) Fate of linear alkylbenzene sulfonates in the environment: a review. Int Biodeter Biodegr 63:981-987

Neilson AH, Allard AS (2008) Environmental degradation and transformation of organic chemicals. Crc Press/Taylor \& Francis, Boca Raton

Nguyen LN, Oh S (2019) Impacts of antiseptic cetylpyridinium chloride on microbiome and its removal efficiency in aerobic activated sludge. Int Biodeter Biodegr 137:23-29

OECD Guidelines for Testing of Chemicals 301: Ready Biodegradability (1992) Organisation for economic co-operation and development, Paris.
Otzen DE (2017) Biosurfactants and surfactants interacting with membranes and proteins: same but different? Biochim Biophys Acta Biomembranes 1859:639-649

Owsianiak M, Chrzanowski Ł, Szulc A, Staniewski J, Olszanowski A, Olejnik-Schmidt AK, Heipieper HJ (2009a) Biodegradation of diesel/biodiesel blends by a consortium of hydrocarbon degraders: effect of the type of blend and the addition of biosurfactants. Biores Technol 100:1497-1500

Owsianiak M, Szulc A, Chrzanowski Ł, Cyplik P, Bogacki M, OlejnikSchmidt AK, Heipieper HJ (2009b) Biodegradation and surfactantmediated biodegradation of diesel fuel by 218 microbial consortia isolated from petroleum-contaminated soils is not correlated to cell surface hydrophobicity. Appl Microbiol Biotechnol 84:545-553

Palmer M, Hatley H (2018) The role of surfactants in wastewater treatment: Impact, removal and future techniques: a critical review. Water Res 147:60-72

Paulo AMS, Aydin R, Dimitrov MR, Vreeling H, Cavaleiro AJ, GarcíaEncina PA, Stams AJM, Plugge CM (2017) Sodium lauryl ether sulfate (SLES) degradation by nitrate-reducing bacteria. Appl Microbiol Biotechnol 101:5163-5173

Pereira LC, de Souza AO, Bernardes MFF, Pazin M, Tasso MJ, Pereira PH, Dorta DJ (2015) A perspective on the potential risks of emerging contaminants to human and environmental health. Environ Sci Pollut Res 22:13800-13823

Peziak D, Piotrowska A, Marecik R, Lisiecki P, Woźniak M, Szulc A, Ławniczak $Ł$, Chrzanowski $Ł$ (2013) Bioavailability of hydrocarbons to bacterial consortia during Triton X-100 mediated biodegradation in aqueous media. Acta Biochim Pol 60:789-793

Rahsepar S, Smit MPJ, Murk AJ, Rijnaarts HHM, Langenhoff AAM (2016) Chemical dispersants: oil biodegradation friend or foe? Mar Pollut Bull 108:113-119

Rebello S, Asok AK, Mundayoor S, Jisha MS (2014) Surfactants: toxicity, remediation and green surfactants. Environ Chem Lett 12:275287

Ren X, Zeng G, Tang L, Wang J, Wan J, Liu Y, Yu J, Yi H, Ye S, Deng R (2018) Sorption, transport and biodegradation - an insight into bioavailability of persistent organic pollutants in soil. Sci Total Environ 610-611:1154-1163

Rios F, Lechuga M, Fernández-Serrano M, Fernández-Arteaga A (2017) Aerobic biodegradation of amphoteric amine-oxide-based surfactants: effect of molecular structure, initial surfactant concentration and $\mathrm{pH}$. Chemosphere 171:324-331

Sakai N, Shirasaka J, Matsui Y, Ramli MR, Yoshida K, Ali Mohd M, Yoneda M (2017) Occurrence, fate and environmental risk of linear alkylbenzene sulfonate in the Langat and Selangor River basins, Malaysia. Chemosphere 172:234-241

Shaharom S, Latif MT, Khan MF, Yusof SNM, Sulong NA, Wahid NBA, Uning R, Suratman S (2018) Surfactants in the sea surface microlayer, subsurface water and fine marine aerosols in different background coastal areas. Environ Sci Pollut Res 25:27074-27089

Sydow M, Szczepaniak Z, Framski G, Staninska J, Owsianiak M, Szulc A, Piotrowska-Cyplik A, Zgoła-Grześkowiak A, Wyrwas B, Chrzanowski L (2015) Persistence of selected ammonium- and phosphonium-based ionic liquids in urban park soil microcosms. Int Biodeterior Biodegradation 103:91-96

Szulc A, Ambrozewicz D, Sydow M, Ławniczak Ł, Piotrowska-Cyplik A, Marecik R, Chrzanowski T (2014) The influence of bioaugmentation and biosurfactant addition on bioremediation efficiency of diesel-oil contaminated soil: feasibility during field studies. J Environ Manage 132:121-128

Szwach I, Lukosek M (2017) Comparative evaluation of environmental impact of selected ethoxylate fatty alcohols and ethoxylate fatty acid methyl esters as nonionic surfactants. PJOES 26:1245-1250

Timmer N, Droge STJ (2017) Sorption of cationic surfactants to artificial cell membranes: comparing phospholipid bilayers with monolayer 
coatings and molecular simulations. Environ Sci Technol 51:28902898

Traverso-Soto JM, Rojas-Ojeda P, Sanz JL, González-Mazo E, LaraMartín PA (2016) Anaerobic degradation of alcohol ethoxylates and polyethylene glycols in marine sediments. Sci Total Environ 544:118-124

Trellu C, Mousset E, Pechaud Y, Huguenot D, van Hullebusch ED, Esposito G, Oturan MA (2016) Removal of hydrophobic organic pollutants from soil washing/flushing solutions: a critical review. J Hazard Mater 306:149-174

Van Loosdrecht MCM, Lyklema J, Norde W, Schraa G, Zehnder AJB (1987) Electrophoretic mobility and hydrophobicity as a measure to predict the initial steps of bacterial adhesion. Appl Environ Microbiol 53:1898-1901

Wilcocks KL, Smart KA (1995) The importance of surface charge and hydrophobicity for the flocculation of chain-forming brewing yeast strains and resistance of these parameters to acid washing. FEMS Microbiol Lett 134:293-297
Wyrwas B, Chrzanowski Ł, Ławniczak Ł, Szulc A, Cyplik P, Białas W, Szymański A, Hołderna-Odachowska A (2011) Utilization of Triton X-100 and polyethylene glycols during surfactant-mediated biodegradation of diesel fuel. J Hazard Mater 197:97-103

Wyrwas B, Dymaczewski Z, Zgoła-Grześkowiak A, Szymański A, Frańska M, Kruszelnicka I, Ginter-Kramarczyk D, Cyplik P, Ławniczak Ł, Chrzanowski Ł (2013) Biodegradation of Triton X100 and its primary metabolites by a bacterial community isolated from activated sludge. J Environ Manage 128:292-299

Xu D, Ni X, Zhang C, Mao J, Song C (2017) Synthesis and properties of biodegradable cationic gemini surfactants with diester and flexible spacers. J Mol Liq 240:542-548

Zembrzuska J, Budnik I, Lukaszewski Z (2016) Monitoring of selected non-ionic surfactants in river water by liquid chromatographytandem mass spectrometry. J Environ Manage 169:247-252

Publisher's note Springer Nature remains neutral with regard to jurisdictional claims in published maps and institutional affiliations. 